\title{
Trocas gasosas e produtividade de três cultivares de meloeiro conduzidas com um e dois frutos por planta
}

\author{
Graciela Maiara Dalastra (*); Márcia de Moraes Echer; Vandeir Francisco Guimarães; \\ Tiago Luan Hachmann; Adriano Mitio Inagaki \\ Universidade Estadual do Oeste do Paraná (UNIOESTE), Caixa Postal 91, 85960-000 Marechal Cândido Rondon (PR), Brasil. \\ (*) Autora correspondente: gradalastra@hotmail.com
}

Recebido: 23/jun./2014; Aceito: 2/set./2014

\begin{abstract}
Resumo
Objetivou-se, no presente trabalho, avaliar as trocas gasosas e sua influência na produtividade e qualidade de cultivares de melão conduzidas com um e dois frutos por planta. O experimento foi conduzido de setembro a dezembro de 2013. Utilizouse o delineamento de blocos ao acaso, em esquema fatorial $3 \times 2$, com seis repetições. No primeiro fator foram alocadas as cultivares de melão pertencentes aos tipos amarelo, rendilhado e pele de sapo e no segundo fator, a condução das plantas com um e dois frutos por planta. Foram utilizadas três cultivares de melão para cada tipo. As avaliações foram realizadas aos 40 e aos 56 dias após o transplantio. As características avaliadas foram: taxa de assimilação líquida de $\mathrm{CO}_{2}(A)$, transpiração foliar $(E)$, condutância estomática $\left(g_{s}\right)$ e concentração interna de $\mathrm{CO}_{2}\left(C_{i}\right)$. A partir dessas medidas foi calculada a eficiência no uso da água (WUE). O teor de sólidos solúveis foi determinado por leitura direta, enquanto que a massa média dos frutos foi mensurada no momento da colheita, estimando-se a produtividade. Diante dos resultados, pode-se concluir que as diferenças nos índices de trocas gasosas para as cultivares de melão do tipo pele de sapo não influenciaram na produtividade e no teor de sólidos solúveis. Como melão do tipo amarelo e do tipo rendilhado recomendam-se as cultivares Goldex e Louis, respectivamente. Independente da cultivar, recomenda-se o cultivo de melão com dois frutos por planta, por assim as plantas apresentarem maior produtividade sem alterar de forma expressiva os índices de trocas gasosas delas.
\end{abstract}

Palavras-chave: Cucumis melo L., taxa assimilatória líquida de $\mathrm{CO}_{2}$, transpiração, condutância estomática, eficiência no uso da água.

\section{Gas exchange and productivity from three cultivars of melon conduced with one and two fruit per plant}

\section{Abstract}

The objective of the present work was to evaluate gas exchange and its influence on productivity and quality of melon cultivars conducted with one and two fruits per plant. The experiment was conducted from September to December, 2013. The experimental design was of randomized blocks in factorial design $3 \times 2$ with six replications. In the first factor were allocated the melon cultivars, belonging to types canary melon, net melon and frog skin melon; and the second factor was the conduction of plants with one and two fruits per plant. Three melon cultivars were used for each type. The evaluations were performed at 40 and 56 days after transplanting. The characteristics evaluated were: $\mathrm{CO}_{2}$ assimilation rate $(A)$, transpiration $(E)$, stomatic conductance (gs), the internal $\mathrm{CO}_{2}$ concentration ( $\mathrm{C}$ ). From these measurements was calculated water use efficiency (EUA). The soluble solids content was determined by direct reading, while the average fruit weight was measured at harvest, estimating productivity. With the results, it can be concluded that differences in gas exchange indexes to cultivars of frog skin melon type have no influence on productivity and soluble solids content. To cultivars of canary melon and net melon types is recommended the Goldex and Louis cultivars respectively. Independent of cultivar is recommended cultivation with two fruits per plant, because its higher productivity and did not change the indices of gas exchange in plants.

Key words: Cucumis melo L., $\mathrm{CO}_{2}$ assimilation rate, transpiration, stomatal conductance, water use efficiency.

\section{INTRODUÇÃO}

O melāo (Cucumis melo L.), originário da África e da Ásia, pertence à família das cucurbitáceas e é uma planta herbácea, anual, rasteira ou trepadora. Os frutos são constituídos de $90 \%$ de água e ricos em vitaminas A, C e E, além de sais minerais e propriedades antioxidantes (Melo et al., 2008).
O meláo tem grande importância para a economia brasileira, pois sua produção não sofre grandes variaçôes de uma safra para outra e ele é uma das culturas de maior crescimento nas exportaçóes de hortaliças do país. O Brasil destaca-se no cenário mundial, sendo o $12 .^{\circ}$ produtor mundial e o maior produtor na América do Sul (FAO, 2011). 
Diante da importância econômica da cultura, existe a necessidade de estudar como os efeitos da temperatura, da umidade relativa do ar e da radiaçáo solar atuam sobre os índices de trocas gasosas dessas plantas. Conhecendo-se como esses fatores ambientais afetam esses índices, podem-se traçar práticas de manejo diferenciadas para a cultura, a fim de otimizá-la, proporcionando aumento da produtividade.

A radiação solar exerce grande influência na cultura do melão e é importante para os processos fotossintéticos relacionados com o acúmulo de área foliar, a fixação de frutos, o teor de açúcar e a coloração da casca (Giehl et al., 2008). Segundo Silva et al. (2003), a taxa de crescimento do meloeiro aumenta sob condiçôes de alta radiação, em função do melhor desempenho na síntese e alocação de fotoassimilados. Marcelis (1992) relata que o crescimento dos frutos é regulado pela disponibilidade de assimilados e pela distribuição proporcional desses entre os frutos e demais órgãos da planta. Esse tipo de análise baseia-se fundamentalmente no fato de aproximadamente $90 \%$ da matéria seca acumulada pelas plantas, ao longo do seu crescimento, resultar da atividade fotossintética, o restante resulta da absorçấo de nutrientes minerais (Benincasa, 2003).

Práticas de manejo como o raleio de frutos podem modificar a taxa fotossintética em plantas cultivadas, sendo uma importante alternativa para se obter ganhos em qualidade e produtividade. Dessa forma, o entendimento de como os fatores climáticos e as práticas de manejo da cultura influenciam nas trocas gasosas torna-se muito importante, uma vez que a otimização desses fatores pode resultar em aumento na taxa de assimilaçáo líquida de $\mathrm{CO}_{2}$, contribuindo de forma direta para o crescimento e desenvolvimento das plantas e, consequentemente, para a qualidade do produto (Salazar, 1978).

A verificação das trocas gasosas é uma importante ferramenta na determinação da adaptação das plantas a determinados ambientes de cultivo, porque a redução na produtividade das plantas pode estar relacionada à reduçáo na atividade fotossintética, podendo ela ser limitada por fatores inerentes ao local de cultivo (Paiva et al., 2005; Peixoto et al., 2002).

Diante da grande importância que a cultura apresenta para a economia nacional e da escassez de informaçóes referentes ao comportamento dos aspectos fisiológicos de diferentes tipos de melão, objetivou-se avaliar os índices de trocas gasosas e sua influência na produtividade e qualidade de cultivares de melão conduzidas com um e dois frutos por planta, em ambiente protegido.

\section{MATERIAL E MÉTODOS}

O experimento foi realizado de setembro a dezembro de 2013, na Estação Experimental de Horticultura e Controle Biológico pertencente à Unioeste, no município de Marechal Cândido Rondon (PR). O clima, classificado segundo
Koppen, é do tipo Cfa, subtropical, com média anual de precipitação de $1.700 \mathrm{~mm}$, mantendo-se a média anual de temperatura entre $22^{\circ} \mathrm{C}$ e $23^{\circ} \mathrm{C}$ (Caviglione et al., 2000).

$\mathrm{O}$ trabalho foi conduzido no interior de estufa com teto em arco, revestida com filme de polietileno de baixa densidade ( $150 \mu$ de espessura) e laterais protegidas com tela branca de $40 \%$ de sombreamento.

$\mathrm{O}$ delineamento experimental adotado foi de blocos ao acaso em esquema fatorial $3 \times 2$, com seis repetiçóes. No primeiro fator foram alocadas as cultivares de melão, pertencentes aos tipos amarelo, rendilhado e pele de sapo, e no segundo fator, a condução de plantas com um e dois frutos por planta. Foram utilizados três cultivares de melão para o tipo amarelo (AF 4945, Gold Mine e Goldex), três para o rendilhado (Acclain, Louis e Olimpic Express) e três para o pele de sapo (Medellin, Grand Prix e Sancho).

As mudas foram produzidas em bandejas de poliestireno expandido de 128 células, contendo substrato comercial. Essas permaneceram em casa de vegetação até o momento do transplantio, que ocorreu quando as mudas apresentavam a segunda folha verdadeira.

A cultura foi instalada em vasos de polietileno de 12 litros de capacidade, preenchidos com uma mistura de substrato comercial para hortaliças e húmus em proporçôes iguais. Os vasos foram dispostos no espaçamento de 1,20 m entre linhas e $0,5 \mathrm{~m}$ entre plantas. Para caracterização química da mistura utilizada foi coletada uma amostra, cuja análise apresentou os seguintes resultados: $\mathrm{P}=14,27 \mathrm{mg} \mathrm{dm}^{-3}$; $\mathrm{K}=3,25 \mathrm{cmol} \mathrm{dm}_{c}^{-3} ; \mathrm{Ca}^{2+}=3,41 \mathrm{cmol} \mathrm{dm}_{c}^{-3} ; \mathrm{N}=0,826$ $\mathrm{cmol}_{\mathrm{c}} \mathrm{dm}^{-3} ; \mathrm{Mg}^{2+}=3,17 \mathrm{mg} \mathrm{dm}{ }^{-3} ; \mathrm{Cu}=15,33 \mathrm{mg} \mathrm{dm}^{-3}$; $\mathrm{Zn}=60,26 \mathrm{mg} \mathrm{dm}^{-3} ; \mathrm{Mn}=9,70 \mathrm{mg} \mathrm{dm}^{-3} ; \mathrm{Fe}=30,98 \mathrm{mg}$ $\mathrm{dm}^{-3}$.

A irrigação foi realizada via gotejamento, utilizando-se fita flexível com vazão de 1,6 L h h e emissores espaçados a cada $0,50 \mathrm{~m}$. A quantidade de água demandada foi controlada através de tensiômetros do modelo WATERMETER WS-76 $\left(\mathrm{P}^{*}\right)$, que foram instalados dentro dos vasos. A adubação foi realizada via fertirrigação, duas vezes por semana, seguindo-se a recomendaçáo de Trani et al. (2011), adaptada para o presente experimento, segundo os estádios de desenvolvimento da cultura. Durante o ciclo da cultura foram aplicados $7,47 \mathrm{~kg}$ de fosfato monopotássico, $56,29 \mathrm{~kg}$ de nitrato de potássio, $26,75 \mathrm{~kg}$ de nitrato de cálcio, $28,92 \mathrm{~kg}$ de sulfato de magnésio e $1 \mathrm{~kg}$ de ácido bórico.

As plantas foram conduzidas verticalmente, em haste única, com uso de fitilhos plásticos, até a altura de 1,80 m do vaso, quando foi realizada a poda da gema apical. O tratamento com número de frutos foi fixado nos ramos secundários emitidos entre o $4 .^{\circ}$ e $6 .^{\circ}$ entrenós. Quando os frutos apresentaram 3 a $4 \mathrm{~cm}$ de diâmetro, seus ramos foram podados, deixando-se duas folhas após o ponto de inserção do fruto na haste. Todas as demais ramificaçóes foram mantidas com uma folha.

Para auxiliar na polinização, uma colmeia de abelha (Apis mellifera) foi colocada na entrada do ambiente. $\mathrm{O}$ 
controle de pragas foi realizado de acordo com a necessidade da cultura, sendo realizadas duas aplicaçóes de inseticidas, aos 10 e 37 dias após o transplantio (DAT), para efetuar o controle de pulgão-verde (Myzus persicae), trips (Thrips tabaci) e mosca-branca (Bemisia tabaci biótipo B).

A determinação dos índices de troca gasosas: taxa de assimilação líquida de $\mathrm{CO}_{2}(A)$, transpiração foliar $(E)$, condutância estomática $\left(g_{s}\right)$ e concentração interna de $\mathrm{CO}_{2}$ $\left(C_{\mathrm{i}}\right)$, foi realizada na quarta folha totalmente expandida a partir do ápice da planta, aos 40 e 56 dias após o transplantio das mudas, o que coincidiu com o período de pleno crescimento dos frutos e início de seu amadurecimento, respectivamente. As medidas foram realizadas em dias ensolarados e sem nebulosidade, das 9 horas às 11 horas da manhá. Os índices foram avaliados utilizando-se um analisador portátil de fotossíntese por radiação infravermelha (Infra Red Gas Analyser - IRGA, modelo Li-6400XT, LI-COR). Com os índices de trocas gasosas foi determinada a eficiência de uso da água $(\mathrm{A} / \mathrm{E})$.

Durante o período em que foram realizadas as avaliaçóes das trocas gasosas, a temperatura do ar oscilou entre $29,4^{\circ} \mathrm{C}$ e $33,8^{\circ} \mathrm{C}$ na primeira avaliação, na segunda avaliação, as temperaturas variaram de $34,3{ }^{\circ} \mathrm{C}$ a $37,1^{\circ} \mathrm{C}$. A umidade relativa média do ar foi de $60,6 \%$ aos 40 DAT e de $61,8 \%$ aos 56 DAT. A densidade de fótons do meio externo proporcionada pelo aparelho apresentou uma média de $839,8 \mu \mathrm{mol} \mathrm{m}^{-2} \mathrm{~s}^{-1}$ aos 40 DAT e de $695,6 \mu \mathrm{mol} \mathrm{m}^{-2} \mathrm{~s}^{-1}$ aos
56 DAT. O fluxo de fótons (PPFD) mantido na câmara do IRGA foi de $1.200 \mu \mathrm{mol} \mathrm{m}{ }^{-2} \mathrm{~s}^{-1}$ nas duas avaliaçóes

A colheita dos frutos iniciou-se aos 56 DAT e prolongou-se até os 72 DAT, sendo realizada de acordo com o amadurecimento dos frutos. Depois de colhidos, os frutos foram levados para laboratório onde inicialmente foi mensurado o teor de sólidos solúveis ( ${ }^{\circ}$ Brix) por leitura direta no extrato do suco, com auxílio de um refratômetro digital. Foi ainda mensurada a massa média dos frutos e posteriormente estimada a produtividade em $\mathrm{kg} \mathrm{m}^{-2}$.

Depois de tabulados, os dados foram submetidos à análise de variância e as médias comparadas pelo teste de Tukey ( $\mathrm{p}>0,05)$. Utilizou-se o programa estatístico SISVAR 5.3 (Ferreira, 2011).

\section{RESULTADOS E DISCUSSÃO}

$\mathrm{Na}$ determinação dos índices de trocas gasosas, sólidos solúveis, massa média de fruto e produtividade, realizados aos 40 e 56 DAT, não foi observada interação significativa entre cultivares de meláo do tipo pele de sapo e número de frutos por planta, sendo os fatores estudados separadamente (Tabelas 1 e 2).

Observando-se os resultados apresentados nas tabelas 1 e 2 verifica-se que aos 40 DAT e aos 56 DAT houve efeito significativo das cultivares para taxa de assimilação líquida

Tabela 1. Taxa de assimilação líquida $\mathrm{CO}_{2}(A)$, transpiração foliar $(E)$, condutância estomática $(g)$, concentração interna de $\mathrm{CO}_{2}\left(C_{\mathrm{i}}\right)$ e eficiência do uso da água (WUE) em função das cultivares de meláo do tipo pele de sapo e do número de frutos por planta aos 40 DAT

\begin{tabular}{|c|c|c|c|c|c|}
\hline Cultivar & A & E & $\mathbf{g}_{\mathrm{s}}$ & $C_{i}$ & WUE \\
\hline Sancho & $26,54 \mathrm{a}$ & 8,08 a & $0,57 \mathrm{a}$ & $246,75 a$ & $3,30 a$ \\
\hline Medellin & $23,54 \mathrm{~b}$ & 7,49 a & $0,47 a$ & $238,18 a$ & $3,15 a$ \\
\hline Grand Prix & $24,09 a b$ & 7,92 a & $0,49 a$ & $242,38 a$ & $3,06 a$ \\
\hline Número de frutos por planta & A & $\mathbf{E}$ & g & C & WUE \\
\hline Um fruto & $24,85 \mathrm{a}$ & 8,09 a & $0,55 \mathrm{a}$ & $248,73 a$ & 3,08 \\
\hline Dois frutos & $24,60 \mathrm{a}$ & $7,57 \mathrm{a}$ & $0,48 \mathrm{a}$ & $236,14 b$ & 3,26 \\
\hline CV(\%) & 11,46 & 11,61 & 22,62 & 6,54 & 8,81 \\
\hline
\end{tabular}

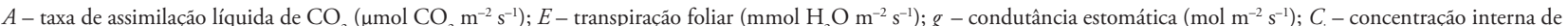
$\mathrm{CO}_{2}\left(\mathrm{mmol} \mathrm{m}^{-2} \mathrm{~s}^{-1}\right) ; W U E$ - eficiência do uso da água $\left(\mathrm{mmol} \mathrm{CO}_{2} \mathrm{~mol}^{-1} \mathrm{H}_{2} \mathrm{O}\right)$; DAT - dias após o transplantio; médias seguidas de mesma letra na coluna năo diferem entre si pelo teste de Tukey a $5 \%$ de probabilidade.

Tabela 2. Taxa de assimilação líquida $\mathrm{CO}_{2}(A)$, transpiração foliar $(E)$, condutância estomática $(g)$, concentração interna de $\mathrm{CO}_{2}\left(C_{\mathrm{i}}\right)$, eficiência do uso da água (WUE), massa média de fruto (MFF) e produtividade (PROD) em funçáo das cultivares de melão do tipo pele de sapo e número de frutos aos 56 DAT

\begin{tabular}{lcccccccc}
\multicolumn{1}{c}{ Cultivar } & $\mathbf{A}$ & $\mathbf{E}$ & $\mathbf{g}_{\mathbf{s}}$ & $\mathbf{C}_{\mathbf{i}}$ & WUE & SS & MFF & PROD \\
Sancho & $19,16 \mathrm{a}$ & $4,41 \mathrm{a}$ & $0,18 \mathrm{~b}$ & $162,80 \mathrm{~b}$ & $4,41 \mathrm{a}$ & $13,46 \mathrm{a}$ & $1439,32 \mathrm{a}$ & $3,15 \mathrm{a}$ \\
Medellin & $15,50 \mathrm{~b}$ & $4,48 \mathrm{a}$ & $0,20 \mathrm{ab}$ & $216,86 \mathrm{a}$ & $4,48 \mathrm{a}$ & $13,01 \mathrm{a}$ & $1625,74 \mathrm{a}$ & $3,35 \mathrm{a}$ \\
Grand Prix & $17,70 \mathrm{ab}$ & $4,64 \mathrm{a}$ & $0,24 \mathrm{a}$ & $212,45 \mathrm{a}$ & $4,64 \mathrm{a}$ & $12,91 \mathrm{a}$ & $1467,00 \mathrm{a}$ & $3,24 \mathrm{a}$ \\
Número de frutos por planta & $\mathbf{A}$ & $\mathbf{E}$ & $\mathbf{g}$ & $\mathbf{C}$ & $\mathbf{E}$ & $\mathbf{S S}$ & MFF & PROD \\
Um fruto & $17,22 \mathrm{a}$ & $4,45 \mathrm{a}$ & $0,22 \mathrm{a}$ & $204,57 \mathrm{a}$ & $4,45 \mathrm{a}$ & $13,54 \mathrm{a}$ & $1778,77 \mathrm{a}$ & $2,96 \mathrm{~b}$ \\
Dois frutos & $17,69 \mathrm{a}$ & $4,58 \mathrm{a}$ & $0,20 \mathrm{a}$ & $190,17 \mathrm{a}$ & $4,58 \mathrm{a}$ & $12,71 \mathrm{~b}$ & $1242,61 \mathrm{~b}$ & $3,54 \mathrm{a}$ \\
$\mathrm{CV}(\%)$ & 14,56 & 9,82 & 26,08 & 23,33 & 9,82 & 5,21 & 13,89 & 15,51 \\
\hline
\end{tabular}

$A$ - taxa de assimilação líquida de $\mathrm{CO}_{2}\left(\mu \mathrm{mol} \mathrm{CO} \mathrm{m}^{-2} \mathrm{~s}^{-1}\right) ; C_{\mathrm{i}}$ - concentração interna de $\mathrm{CO}_{2}\left(\mathrm{mmol} \mathrm{m}^{-2} \mathrm{~s}^{-1}\right) ; E-$ transpiração foliar $\left(\mathrm{mmol} \mathrm{H}_{2} \mathrm{O} \mathrm{m}^{-2} \mathrm{~s}^{-1}\right) ; g-\mathrm{condutância}_{\mathrm{s}}$ estomática $\left(\mathrm{mol} \mathrm{m}^{-2} \mathrm{~s}^{-1}\right)$; WUE - eficiência do uso da água $\left(\mathrm{mmol} \mathrm{CO}_{2} \mathrm{~mol}^{-1} \mathrm{H}_{2} \mathrm{O}\right) ; \mathrm{SS}$ - teor de sólidos solúveis ( ${ }^{\circ}$ Brix); MFF - massa média de frutos (g); PROD - produtividade $\left(\mathrm{kg} \mathrm{m}^{-2}\right)$; DAT - dias após o transplantio; médias seguidas de mesma letra na coluna não diferem entre si pelo teste de Tukey a $5 \%$ de probabilidade. 
de $\mathrm{CO}_{2}(A)$, sendo que elas apresentaram comportamento semelhante em ambas as épocas de avaliação. A diferença observada na taxa de assimilaçáo líquida de $\mathrm{CO}_{2}$ entre as cultivares náo repercutiu em aumento nos teores de sólidos solúveis, na massa média dos frutos e na produtividade. Dessa forma, pode-se inferir que nas condiçôes em que o experimento foi conduzido, o híbrido Sancho, devido às suas características genéticas, possui maior capacidade de realizar fotossíntese quando comparado ao híbrido Medellin.

Segundo Jadoski et al. (2005), o aumento na taxa de assimilaçáo de $\mathrm{CO}_{2}$ está relacionado à maior concentraçáo de $\mathrm{CO}_{2}$ constatada no interior das folhas, o que pode decorrer do fechamento estomático em resposta aos estresses abióticos.

Quando se leva em consideração as plantas com um e dois frutos, a maior concentração interna de $\mathrm{CO}_{2}\left(C_{\mathrm{i}}\right)$ foi observada em plantas mantidas com apenas um fruto. Nessa situação, o teor de sólidos solúveis e a massa do fruto foram maiores, mas não a produtividade. Segundo Taiz e Zeiger (2006), a concentração interna de $\mathrm{CO}_{2}$ é importante porque a produtividade de uma planta pode ser analisada como o produto da energia solar interceptada e do $\mathrm{CO}_{2}$ fixado durante um período. Na presença de quantidade adequada de luz e ausência de estresse, como déficit hídrico, concentraçóes mais altas de $\mathrm{CO}_{2}$ sustentam taxas fotossintéticas elevadas, enquanto que em concentraçôes intercelulares de $\mathrm{CO}_{2}$ muito baixas a fotossíntese é limitada.

O aumento do número de drenos por planta não influenciou na taxa de assimilaçáo líquida de $\mathrm{CO}_{2}(A)$, transpiração foliar $(E)$, condutância estomática $(g)$ e eficiência do uso da água (WUE) na avaliação realizada aos 40 DAT. A ausência de diferenças significativas nesses índices pode ter ocorrido em funçáo de os frutos estarem em fase inicial de desenvolvimento e, como as plantas de meláo são vigorosas, com um grande número de folhas, de essas suprirem de forma satisfatória a necessidade dos drenos por fotoassimilados.

Apesar da concentração interna de $\mathrm{CO}_{2}\left(C_{\mathrm{i}}\right)$ ter sido menor em plantas mantidas com dois frutos, não houve queda na taxa de assimilação líquida de $\mathrm{CO}_{2}$. Isso pode ser devido às condiçôes de ausência de estresse como déficits hídricos. Segundo Raschke (1979), valores menores de $C_{\mathrm{i}}$ estimulam a abertura dos estômatos, permitindo maior entrada de $\mathrm{CO}_{2}$ para a cavidade subestomática. Apesar de a taxa de assimilação de $\mathrm{CO}_{2}$ não ser diferente entre as plantas com um ou dois frutos, os frutos obtidos de plantas com dois frutos foram menores e com menor ${ }^{\circ}$ Brix, em função da partição dos fotoassimilados entre eles.

$\mathrm{Na}$ tabela 2 são apresentados os dados referentes à avaliação realizada aos 56 DAT. Não foi observada diferença entre as cultivares para transpiração, eficiência do uso da água, teor de sólidos solúveis, massa média de fruto e produtividade.

A concentração interna de $\mathrm{CO}_{2}\left(C_{\mathrm{i}}\right)$ foi maior para as cultivares Medellin e Grand Prix. Para a condutância estomática $\left(\mathrm{g}_{\mathrm{s}}\right)$, o menor valor foi observado para o híbrido Sancho. Apesar da diferença de condutância estomática $\left(\mathrm{g}_{\mathrm{s}}\right)$ entre as cultivares de melão, não foi observada alteração nas taxas de transpiração foliar. No entanto, houve redução na concentração interna de $\mathrm{CO}_{2}$ no mesofilo foliar da cultivar Sancho, provavelmente em função do fechamento estomático. Porém esse mecanismo de fechamento estomático não acarretou em diferenças significativas para a eficiência do uso da água entre as cultivares (Tabela 2).

Daley et al. (1989) relatam que a redução da condutância estomática pode limitar a taxa de retenção de $\mathrm{CO}_{2} \mathrm{e}$, consequentemente, a concentração $\mathrm{C} i$ diminui nos espaços intercelulares devido ao consumo de $\mathrm{CO}_{2}$ pela atividade fotossintética.

De modo geral, as plantas quando estão sob algum tipo de estresse reduzem a condutância estomática e a transpiração e aumentam a eficiência do uso da água. Nessas condiçôes, a taxa de fotossíntese também acaba sendo reduzida (Ferraz et al., 2012), o que não aconteceu com a cultivar Sancho, pois apesar de apresentar menor condutância estomática, essa cultivar não reduziu a taxa de assimilaçáo líquida de $\mathrm{CO}_{2}$. Isso pode ter ocorrido em decorrência do metabolismo dessa planta, que no mesmo ambiente das demais consegue realizar mais fotossíntese, com uma menor abertura estomática e com menos $\mathrm{CO}_{2}$ nos espaços intercelulares sem comprometer a eficiência no uso da água.

Apesar das diferenças observadas entre as cultivares para os índices de trocas gasosas, essas não influenciaram no teor de sólidos solúveis, na massa média dos frutos e na produtividade das cultivares de meláo do tipo pele de sapo.

Para número de frutos por planta, observou-se que o maior teor de sólidos solúveis e a maior massa de frutos ocorreram quando eles foram obtidos de plantas com um fruto, apesar de náo terem ocorrido diferenças para os índices de trocas gasosas, com exceção da concentração interna de $\mathrm{CO}_{2}\left(C_{\mathrm{i}}\right)$, na avaliação aos 40 DAT. A produtividade foi maior em plantas mantidas com dois frutos, apesar da menor massa média dos frutos. Essa menor massa fresca dos frutos se deve à partição dos fotoassimilados entre eles.

Para as cultivares do tipo amarelo (Goldex, AF 4945 e Gold Mine) e para número de frutos por planta não foram observadas diferenças significativas para nenhum dos índices de trocas gasosas determinados na avaliação realizada aos 40 DAT (dados não apresentados). Esses resultados indicam que no horário em que foi realizada a avaliação as cultivares apresentavam comportamento semelhante em relação à taxa de assimilação líquida de $\mathrm{CO}_{2}(A)$, condutância estomática $\left(C_{\mathrm{i}}\right)$, transpiração foliar $(E)$, concentração interna de $\mathrm{CO}_{2}$ e quanto à eficiência do uso da água.

Em relação às cultivares do tipo amarelo, na avaliação realizada aos 56 DAT houve interação entre cultivares e número de frutos por planta para transpiração foliar $(E)$, eficiência no uso de água (WUE) e massa média dos frutos (Tabela 3).

As cultivares Goldex e Gold Mine, quando conduzidas com um fruto por planta, apresentaram maior transpiração e menor eficiência no uso de água. Esse aumento da transpiração pode ter ocorrido devido às altas temperaturas registradas 
nesse período de avaliação (temperatura média do ar de $\left.35,8^{\circ} \mathrm{C}\right)$.

Quando as cultivares de melão são comparadas, observa-se que não ocorreram diferenças significativas para eficiência do uso da água, quando conduzidas com dois frutos por planta. No entanto, as cultivares Goldex e AF 4945 apresentaram maior transpiração.

A cultivar Goldex apresentou menor eficiência no uso de água quando conduzida com um fruto, contudo ela apresentou maior massa média de frutos. $\mathrm{O}$ mesmo não foi observado para a cultivar Gold Mine. Isso confirma que a diferença genética entre as cultivares leva a respostas distintas em função das condições ambientais às quais elas são expostas.

Observando-se a tabela 4 verifica-se que não houve diferença significativa para taxa de assimilação líquida de $\mathrm{CO}_{2}(A)$, condutância estomática $\left(g_{\mathrm{s}}\right)$, concentração interna de $\mathrm{CO}_{2}\left(C_{\mathrm{i}}\right)$, sólidos solúveis (SS) e produtividade (PROD) entre as cultivares. $\mathrm{O}$ mesmo foi observado para as plantas com um e com dois frutos, com exceção dos sólidos solúveis e da produtividade.

Embora a cultivar Goldex não tenha diferido das demais cultivares em relação aos índices de trocas gasosas, essa cultivar, realizando a mesma quantidade de fotossíntese, teve maior capacidade de transformar e acumular fotoassimilados, comprovada pelo maior valor de teor de sólidos solúveis que essa cultivar proporcionou aos frutos de meláo.

O maior teor de sólidos solúveis ocorreu quando as plantas foram conduzidas com apenas um fruto, enquanto que a produtividade foi maior quando as plantas foram conduzidas com dois frutos. Apesar da ausência de diferenças entre as taxas de assimilaçáo líquida, ela foi suficiente para manter o maior número de drenos por planta, apesar da menor massa média obtida por fruto.

Outra consideraçáo a ser feita é que nas condiçóes de estudo o maior número de drenos fisiológicos (plantas

Tabela 3. Transpiração foliar $(E)$, eficiência do uso da água (WUE) e massa média de frutos por planta em função das cultivares de melão do tipo amarelo e do número de frutos por planta aos 56 DAT

\begin{tabular}{|c|c|c|c|c|c|c|}
\hline \multirow{3}{*}{ Cultivares } & \multicolumn{2}{|c|}{ E } & \multicolumn{2}{|c|}{ WUE } & \multicolumn{2}{|c|}{ MMF } \\
\hline & \multicolumn{2}{|c|}{ Número de frutos } & \multicolumn{2}{|c|}{ Número de frutos } & \multicolumn{2}{|c|}{ Número de frutos } \\
\hline & Um fruto & Dois frutos & Um fruto & Dois frutos & Um fruto & Dois frutos \\
\hline Goldex & $4,50 \mathrm{abA}$ & $4,43 a b A$ & $3,56 \mathrm{bB}$ & 4,32 aA & $1420,52 \mathrm{aA}$ & $847,33 \mathrm{aB}$ \\
\hline AF 4945 & $4,42 \mathrm{bA}$ & $4,70 \mathrm{aA}$ & $4,24 \mathrm{aA}$ & 3,98 aA & $1235,59 \mathrm{bA}$ & $854,63 \mathrm{aB}$ \\
\hline Gold Mine & $5,11 \mathrm{aA}$ & 4,07 bB & $3,45 \mathrm{bA}$ & $3,86 \mathrm{aA}$ & $1168,21 \mathrm{bA}$ & $974,54 \mathrm{aB}$ \\
\hline CV(\%) & \multicolumn{2}{|c|}{9,63} & \multicolumn{2}{|c|}{11,69} & \multicolumn{2}{|c|}{11,32} \\
\hline
\end{tabular}

$E$ - transpiração foliar $\left(\mathrm{mmol} \mathrm{H}_{2} \mathrm{O} \mathrm{m}^{-2} \mathrm{~s}^{-1}\right)$; WUE - eficiência do uso da água (mmol $\mathrm{CO}_{2} \mathrm{~mol}^{-1} \mathrm{H}_{2} \mathrm{O}$ ); $\mathrm{MFF}$ - massa média de frutos (g); DAT - dias após o transplantio; médias seguidas de mesma letra minúscula na coluna e maiúscula na linha não diferem entre si pelo teste de Tukey a $5 \%$ de probabilidade.

Tabela 4. Taxa de assimilação líquida de $\mathrm{CO}_{2}(A)$, condutância estomática $(g)$, concentração interna de $\mathrm{CO}_{2}\left(C_{\mathrm{i}}\right)$, teor de sólidos solúveis (SS) e produtividade (PROD) em função das cultivares de melão do tipo amarelo e do número de frutos por planta aos 56 DAT

\begin{tabular}{|c|c|c|c|c|c|}
\hline Cultivar & A & $\mathbf{g}_{\mathrm{s}}$ & $C_{i}$ & SS & PROD \\
\hline Goldex & $17,61 \mathrm{a}$ & $0,25 \mathrm{a}$ & $216,45 \mathrm{a}$ & $14,46 \mathrm{a}$ & $2,41 \mathrm{a}$ \\
\hline AF 4945 & $18,67 \mathrm{a}$ & $0,21 \mathrm{a}$ & $198,17 \mathrm{a}$ & $13,29 b$ & $2,50 \mathrm{a}$ \\
\hline Gold Mine & $17,73 \mathrm{a}$ & $0,28 \mathrm{a}$ & $224,38 \mathrm{a}$ & $12,59 \mathrm{c}$ & $2,50 \mathrm{a}$ \\
\hline Número de frutos por planta & A & g & C & SS & PROD \\
\hline Um fruto & $17,53 \mathrm{a}$ & $0,30 \mathrm{a}$ & $240,90 \mathrm{a}$ & $13,87 \mathrm{a}$ & $2,05 \mathrm{~b}$ \\
\hline Dois frutos & $17,81 \mathrm{a}$ & $0,26 \mathrm{a}$ & $185,10 \mathrm{a}$ & $13,02 \mathrm{~b}$ & $2,88 \mathrm{a}$ \\
\hline CV(\%) & 14,06 & 24,74 & 28,17 & 3,74 & 16,89 \\
\hline
\end{tabular}

$A$ - taxa de assimilaçáo líquida de $\mathrm{CO}_{2}\left(\mu \mathrm{mol} \mathrm{CO} \mathrm{m}^{-2} \mathrm{~s}^{-1}\right) ; g$ - condutância estomática $\left(\mathrm{mol} \mathrm{m}^{-2} \mathrm{~s}^{-1}\right) ; C_{\mathrm{i}}$ - concentração interna de $\mathrm{CO}_{2}\left(\mathrm{mmol} \mathrm{m}^{-2} \mathrm{~s}^{-1}\right) ; \mathrm{SS}_{-}$teor de sólidos solúveis ( ${ }^{\circ}$ rix); PROD - produtividade $\left(\mathrm{kg} \mathrm{m}^{-2}\right)$; DAT - dias após o transplantio; médias seguidas de mesma letra na coluna náo diferem entre si pelo teste de Tukey a $5 \%$ de probabilidade.

Tabela 5. Taxa de assimilação líquida de $\mathrm{CO}_{2}(A)$, transpiração foliar $(E)$, condutância estomática $\left(g_{s}\right)$, concentração interna de $\mathrm{CO}_{2}\left(C_{\mathrm{i}}\right)$ e eficiência do uso da água (WUE) em funçáo das cultivares de meláo do tipo rendilhado e do número de frutos por planta aos 40 DAT

\begin{tabular}{|c|c|c|c|c|c|}
\hline Cultivares & A & $\mathrm{E}$ & $\mathbf{g}_{\mathrm{s}}$ & $C_{i}$ & WUE \\
\hline Olimpic Express & $25,67 \mathrm{a}$ & $8,08 \mathrm{a}$ & $0,54 \mathrm{a}$ & $250,87 a$ & $3,19 a$ \\
\hline Louis & $23,06 \mathrm{a}$ & $7,17 \mathrm{~b}$ & $0,41 \mathrm{a}$ & $232,72 a$ & $3,24 \mathrm{a}$ \\
\hline Acclain & $23,30 \mathrm{a}$ & $7,72 a b$ & $0,53 \mathrm{a}$ & $248,47 \mathrm{a}$ & $3,03 \mathrm{a}$ \\
\hline Número de frutos por planta & A & E & $\mathbf{g}_{\mathrm{s}}$ & C & WUE \\
\hline Um fruto & $24,05 \mathrm{a}$ & $7,57 \mathrm{a}$ & $0,49 \mathrm{a}$ & $245,46 \mathrm{a}$ & $3,18 \mathrm{a}$ \\
\hline Dois frutos & $23,97 \mathrm{a}$ & $7,74 \mathrm{a}$ & $0,49 a$ & $242,58 \mathrm{a}$ & $3,12 \mathrm{a}$ \\
\hline CV(\%) & 12,02 & 11,16 & 28,38 & 7,35 & 9,20 \\
\hline
\end{tabular}

$A$ - taxa de assimilaçáo líquida de $\mathrm{CO}_{2}\left(\mu \mathrm{mol} \mathrm{CO} \mathrm{m}^{-2} \mathrm{~s}^{-1}\right) ; E$ - transpiração foliar $\left(\mathrm{mmol} \mathrm{H}_{2} \mathrm{O} \mathrm{m}^{-2} \mathrm{~s}^{-1}\right) ; g$ - condutância estomática $\left(\mathrm{mol} \mathrm{m}^{-2} \mathrm{~s}^{-1}\right) ; C$ - concentração interna de $\mathrm{CO}_{2}\left(\mathrm{mmol} \mathrm{m}^{-2} \mathrm{~s}^{-1}\right)$; WUE - eficiência do uso da água $\left(\mathrm{mmol} \mathrm{CO} \mathrm{mol}^{-1} \mathrm{H}_{2} \mathrm{O}\right)$; DAT - dias após o transplantio; médias seguidas de mesma letra na coluna não diferem entre si pelo teste de Tukey a $5 \%$ de probabilidade. 
conduzidas com dois frutos) não foi determinante para promover o aumento na capacidade fotossintética da folha. Dessa forma, os drenos fisiológicos acabaram competindo pelos fotoassimilados produzidos, gerando frutos menores, apesar da maior produtividade.

$\mathrm{Na}$ tabela 5 são apresentados os resultados dos índices de trocas gasosas das cultivares de meláo do tipo rendilhado e de plantas conduzidas com um e com dois frutos aos 40 DAT. Houve efeito significativo para transpiração $(E)$, sendo que a cultivar Olimpic Express apresentou maior valor. Essa diferença não influenciou nos demais índices de trocas gasosas. Apesar de essas plantas terem tido maior transpiração, isso não acarretou em perdas excessivas de água ou então no fechamento estomático, o que levaria à redução da taxa de assimilaçáo líquida de $\mathrm{CO}_{2}$.

No horário em que foi realizada a avaliação de trocas gasosas aos 40 DAT, a temperatura média registrada foi de $31,7^{\circ} \mathrm{C}$. Embora essa temperatura náo seja considerada prejudicial para o meloeiro, pode ser que o híbrido Olimpic Express seja mais sensível à alta temperatura, o que resultou em maior transpiração foliar em relação aos demais híbridos desse tipo de meláo. De acordo com Inoue e Ribeiro (1988), a transpiração é um fenômeno influenciado principalmente pela temperatura e a saturação de vapor d'água. Sob as mesmas condiçóes, diferenças na transpiração podem indicar um mecanismo estomático com maior ou menor eficiência, implicando na economia de água pela planta.

Tabela 6. Taxa de assimilaçáo líquida de $\mathrm{CO}_{2}(A)$ em função das cultivares de meláo do tipo rendilhado e do número de frutos por planta aos 56 DAT

\begin{tabular}{lcc}
\multirow{2}{*}{ Cultivares } & \multicolumn{2}{c}{ A } \\
\cline { 2 - 3 } & \multicolumn{2}{c}{ Número de frutos } \\
\cline { 2 - 3 } Olimpic Express & Um fruto & Dois frutos \\
\hline Acclain & $19,00 \mathrm{aA}$ & $18,74 \mathrm{aA}$ \\
\hline Louis & $15,36 \mathrm{bB}$ & $19,83 \mathrm{aA}$ \\
\hline CV(\%) & $13,29 \mathrm{bB}$ & $17,32 \mathrm{aA}$ \\
\hline
\end{tabular}

$A$ - taxa de assimilação líquida de $\mathrm{CO}_{2}\left(\mu \mathrm{mol} \mathrm{CO}_{2} \mathrm{~m}^{-2} \mathrm{~s}^{-1}\right)$; DAT - dias após o transplantio; médias seguidas de mesma letra minúscula na coluna e maiúscula na linha nāo diferem entre si pelo teste de Tukey a $5 \%$ de probabilidade.
Não houve diferenças para os índices de trocas gasosas entre as plantas mantidas com um e com dois frutos. Isso pode ter ocorrido em função de todas as plantas estarem sob a mesma condição (início do desenvolvimento dos frutos) e sem nenhum tipo de estresse no momento da avaliação, fosse ele excesso de radiação, temperatura, fosse falta de água (Tabela 5).

$\mathrm{Na}$ determinação dos índices de trocas gasosas realizada aos 56 DAT houve interaçáo entre as cultivares de meláo do tipo rendilhado e o número de frutos por planta, para taxa de assimilação líquida de $\mathrm{CO}_{2}(A)$ (Tabela 6). Para os demais índices não foram observadas diferenças entre as cultivares (Tabela 7).

Comparando-se as plantas das cultivares Acclain e Louis mantidas com um e com dois frutos, a maior taxa de assimilação líquida de $\mathrm{CO}_{2}(A)$ foi verificada nas plantas com dois frutos (Tabela 6).

Entre as cultivares de meloeiro mantidas com um fruto por planta, verificou-se que o maior valor para taxa assimilação líquida de $\mathrm{CO}_{2}(A)$ foi observado para a cultivar Olimpic Express. Para essa mesma variável, as cultivares Olimpic Express, Acclain e Louis náo diferiram entre si quando as plantas foram conduzidas com dois frutos.

Nesse caso, diferentemente do observado para os outros tipos de melão, o número de drenos fisiológicos para as cultivares Acclain e Louis foi determinante na taxa de assimilaçáo líquida de $\mathrm{CO}_{2}(A)$. Contudo, vale ressaltar que as diferenças náo foram em funçáo do aumento da taxa de assimilação líquida de $\mathrm{CO}_{2}(A)$ quando as plantas foram conduzidas com dois frutos, e sim porque a taxa de assimilação líquida de $\mathrm{CO}_{2}(A)$ de plantas com um fruto foi inferior.

O maior valor de sólidos solúveis foi obtido para os frutos da cultivar Louis. Não foi observada diferença entre as cultivares de meloeiro do tipo rendilhado para massa média de fruto e produtividade. No entanto, as plantas mantidas com um fruto apresentaram maior teor de sólidos solúveis e maior massa média de fruto, porém com menor produtividade (Tabela 7).

Tabela 7. Condutância estomática $\left(g_{\mathrm{s}}\right)$, concentração interna de $\mathrm{CO}_{2}\left(C_{\mathrm{i}}\right)$, transpiração foliar $(E)$, eficiência do uso da água (WUE), teor de sólidos solúveis (SS), massa média de frutos (MFF) e produtividade (PROD) em função das cultivares de melão do tipo rendilhado e do número de frutos por planta aos 56 DAT

\begin{tabular}{lccccccc}
\multicolumn{1}{c}{ Cultivar } & $\mathbf{g}_{\mathbf{s}}$ & $\mathbf{C}_{\mathrm{i}}$ & $\mathbf{E}$ & WUE & SS & MFF & PROD \\
Olimpic Express & $0,29 \mathrm{a}$ & $224,04 \mathrm{a}$ & $4,74 \mathrm{a}$ & $4,04 \mathrm{a}$ & $10,62 \mathrm{c}$ & $1234,31 \mathrm{a}$ & $2,75 \mathrm{a}$ \\
Acclain & $0,25 \mathrm{a}$ & $249,17 \mathrm{a}$ & $4,90 \mathrm{a}$ & $3,58 \mathrm{a}$ & $11,69 \mathrm{~b}$ & $1163,83 \mathrm{a}$ & $2,66 \mathrm{a}$ \\
Louis & $0,23 \mathrm{a}$ & $231,24 \mathrm{a}$ & $4,44 \mathrm{a}$ & $3,46 \mathrm{a}$ & $14,72 \mathrm{a}$ & $1148,14 \mathrm{a}$ & $2,75 \mathrm{a}$ \\
$\quad$ Número de frutos por planta & $\mathbf{g}$ & $\mathbf{C}$ & $\mathbf{E}$ & WUE & SS & MFF & PROD \\
Um fruto & $0,27 \mathrm{a}$ & $245,32 \mathrm{a}$ & $4,50 \mathrm{a}$ & $3,54 \mathrm{a}$ & $13,02 \mathrm{a}$ & $1367,98 \mathrm{a}$ & $2,16 \mathrm{~b}$ \\
Dois frutos & $0,57 \mathrm{a}$ & $224,32 \mathrm{a}$ & $4,89 \mathrm{a}$ & $3,85 \mathrm{a}$ & $11,67 \mathrm{~b}$ & $996,20 \mathrm{~b}$ & $3,27 \mathrm{a}$ \\
$\mathrm{CV}(\%)$ & 14,59 & 18,09 & 15,51 & 19,29 & 6,51 & 13,09 & 16,61 \\
\hline
\end{tabular}

$g$ - condutância estomática $\left(\mathrm{mol} \mathrm{m}^{-2} \mathrm{~s}^{-1}\right) ; C_{\mathrm{i}}$ - concentração interna de $\mathrm{CO}_{2}\left(\mathrm{mmol} \mathrm{m}^{-2} \mathrm{~s}^{-1}\right) ; E$ - transpiração foliar $\left(\mathrm{mmol} \mathrm{H}_{2} \mathrm{O}^{-2} \mathrm{~s}^{-1}\right)$; WUE - eficiência do uso da água (mmol $\mathrm{CO}_{2} \mathrm{~mol}^{-1} \mathrm{H}_{2} \mathrm{O}$ ); $\mathrm{SS}$ - teor de sólidos solúveis ( ${ }^{\circ}$ Brix); MFF - massa média de frutos (g); PROD - produtividade ( $\mathrm{kg} \mathrm{m}^{-2}$ ); DAT - dias após o transplantio; médias seguidas de mesma letra na coluna năo diferem entre si pelo teste de Tukey a $5 \%$ de probabilidade. 
Embora tenham ocorrido diferenças na taxa de assimilação líquida de $\mathrm{CO}_{2}$ entre as cultivares e conforme o número de frutos por planta, essas não repercutiram em diferenças na produtividade final entre as cultivares, afetada apenas pelo número de frutos por planta, demonstrando-se que maior número de frutos por área é mais determinante na produtividade do que a atividade fotossintética.

\section{CONCLUSÃO}

As diferenças nos índices de trocas gasosas para as cultivares de melão do tipo pele de sapo não influenciaram na produtividade nem no teor de sólidos solúveis.

Como cultivares de melão do tipo amarelo e rendilhado recomendam-se as cultivares Goldex e Louis, respectivamente, pois apresentam maior teor de sólidos solúveis.

Os índices de trocas gasosas, independentemente da cultivar avaliada, não apresentaram expressivas diferenças em função da condução de plantas com um ou dois frutos.

O cultivo de melão com dois frutos por planta é mais vantajoso, por apresentar maior produtividade, mantendo valores de sólidos solúveis totais satisfatórios.

\section{REFERÊNCIAS}

BENINCASA, M.M.P. Análise de crescimento de plantas: noçōes básicas. 2. ed. Jaboticabal: Funep, 2003. 41p.

CAVIGLIONE, J.H.; KIHL, L.R.B.; CARAMORI, P.H.; OLIVEIRA, D. Cartas climáticas do Paraná. Londrina: IAPAR, 2000. Disponível em: http://www.iapar.br/modules/conteudo/conteudo.php?conteudo=677. Acesso em: 3 ago. 2013.

DALEY, P.F.; RASCHKE, K.; BALL, J.Y.; BERRY, J.A. Topography of photosyn the tic activity of leaves obtained from video images of chlorophyll fluorescence. Plant Physiology, v.90, p.1233-1238, 1989. PMid:16666912 PMCid:PMC1061872. http://dx.doi.org/10.1104/ pp.90.4.1233

FERRAZ, R.L.S.; MELO, A.S.; SUASSUNA, J.F.; BRITO, M.E.B.; FERNANDES, P.D.; NUNES JÚNIOR, E.S. Trocas gasosas e eficiência fotossintética em ecótipos de feijoeiro cultivados no semiárido. Revista Pesquisa Tropical, v.42, p.181-188, 2012. http://dx.doi.org/10.1590/ S1983-40632012000200010

FERREIRA, D.F. Sisvar: a computer statistic analysis system. Ciência e Agrotecnologia, v.35, p.1039-1042, 2011.
FOOD AND AGRICULTURE ORGANIZATION OF THE UNITED NATIONS - FAO. FAOSTAT: Agricultural Statistics Data base 2011. Disponível em: <http://faostat.fao.org/faostat>. Acesso em: 5 mar. 2013.

GIEHL, R.F.H.; FAGAN, E.B.; EISERMANN, A.C.; BRACKMANN, A.; MEDEIROS, S.P.; MANFRON, P.A. Crescimento e mudanças físico-químicas durante a maturação de frutos de meloeiro (Cucumis melo var. cantalupensis Naud) híbrido torreon. Ciência e Agrotecnologia, v.32, p.371-377, 2008. http://dx.doi.org/10.1590/ S1413-70542008000200004

JADOSKI, S.O.; KLAR, A.E.; SALVADOR, E.D. Relaçôes hídricas e fisiológicas em plantas de pimentão ao longo de um dia. Ambiência, v.1, p.11-19, 2005.

INOUE, M.T.; RIBEIRO, F.A. Fotossíntese e transpiraçáo de clones de Eucalyptu ssp. e E. saligna. Revista do IPEF, v.40, p.15-20, 1988.

MARCELIS, L.F.M.A. Simulation model for dry matter partitioning in cucumber. Annals of Botany, v.70, p.429-435, 1992.

MELO, E.A.; MACIEL, M.I.S.; LIMA, V.L.A.G.; NASCIMENTO, R.J. Capacidade antioxidante de frutas. Revista Brasileira de Ciências Farmacêuticas, v.44, p.193-201, 2008. http://dx.doi.org/10.1590/ S1516-93322008000200005

PAIVA, A.S.; FERNANDES, E.J.; RODRIGUES, T.J.D.; TURCO, J.R.P. Condutância estomática em folhas de feijoeiro submetido a diferentes regimes de irrigação. Engenharia Agrícola, v.25, p.161169, 2005. http://dx.doi.org/10.1590/S0100-69162005000100018

PEIXOTO, P.H.P.; MATTA, F.M.; CAMBRAIA, J. Responses of the photosynthetic apparatus to aluminum stress in two sorghum cultivars. Journal of Plant Nutrition, v.25, p.821-832, 2002. http:// dx.doi.org/10.1081/PLN-120002962

RASCHKE, K. Movements using turgor mechanisms: movements of stomata. In: HAUPT, W.; FEINLEIB, M.E. (Ed.). Encyclopedia of Plant Physiology. Berlin: Springer-Verlag, 1979. p.383-441. (Physiology of Movements. New Series, 7)

SALAZAR, R. Determination of photosynthesis in commercial varieties of papaw (Carica papaya L.) and its possible relationship with the production and quality of the fruits. Revista ICA, v.2, p.291-295, 1978.

SILVA, H.R.; COSTA, N.D.; CARRIJO, O.A. Exigências de clima e solo e época de plantio. In: SILVA, H.R.; COSTA, N.D. Melão: produçấo, aspectos técnicos. (Ed). Brasília: EMBRAPA, 2003. p.2328. (Frutas do Brasil, 33).

TAIZ, L.; ZEIGER, E. Fisiologia vegetal. 3. ed. Porto Alegre: Artmed, 2006. p.174-219.

TRANI, P.E.; TIVELLI, S.W.; CARRIJO, A.O. Fertirrigação em hortaliças. Campinas: Instituto Agronômico, 2011. 58p. (Boletim Técnico IAC, 196) 